\title{
A native-like bispecific antibody suppresses the inflammatory cytokine response by simultaneously neutralizing tumor necrosis factor-alpha and interleukin-17A
}

\author{
Tianshu Xu ${ }^{1}$, Tianlei Ying ${ }^{2}$, Lili Wang ${ }^{2}$, Xiaohua Douglas Zhang ${ }^{3}$, Ying Wang ${ }^{4}$, \\ Lishan Kang ${ }^{5}$, Tao Huang ${ }^{5}$, Liang Cheng ${ }^{5}$, Liping Wang ${ }^{1}$ and Qi Zhao ${ }^{3}$ \\ 1 School of Life Science, Jilin University, Changchun, Jilin, China \\ 2 School of Basic Medical Sciences, Fudan University, Shanghai, China \\ ${ }^{3}$ Faculty of Health Sciences, University of Macau, Taipa, Macau, China \\ ${ }^{4}$ Institute of Chinese Medical Sciences, University of Macau, Taipa, Macau, China \\ ${ }^{5}$ Novo Nordisk Research Centre China, Beijing, China \\ Correspondence to: Qi Zhao, email: zhaoqi@alumni.cuhk.net or qizhao@umac.mo
}

Liping Wang, email: wanglp@jlu.edu.cn

Keywords: bispecific antibody, Fc heterodimerization, TNF-a, IL-17, rheumatoid arthritis, Immunology and Microbiology Section, Immune response, Immunity

$\begin{array}{lll}\text { Received: April 04, } 2017 & \text { Accepted: July 12, } 2017 & \text { Published: August 03, } 2017\end{array}$

Copyright: Xu et al. This is an open-access article distributed under the terms of the Creative Commons Attribution License 3.0 (CC BY 3.0), which permits unrestricted use, distribution, and reproduction in any medium, provided the original author and source are credited.

\section{ABSTRACT}

Anti-tumor necrosis factor (TNF) therapies are successful in the treatment of inflammatory disorders. However, some patients with rheumatoid arthritis (RA) fail to response anti-TNF drugs due to the compensation of other inflammatory signals. In this study, to reduce compensatory responses of interleukin-17A (IL17A) during TNF-a inhibition, we generated an IgG-like bispecific antibodiy (bsAb) against TNF-a and IL-17A through a combination method of electrostatic Fc pairing and light chain crossover. This bsAb exhibited relatively high stability comparable to natural IgG antibodies, and retained the unaltered affinities to both of two targets. BsAb significantly decreased not only the expression level of neutrophil or Th17 chemokines, but also the secretion of IL-6/IL-8 on fibroblast-like synoviocytes (FLS) from a patient with RA. Meanwhile, TNF-a-mediated cellular cytotoxicity of fibroblasts was neutralized by bsAb. Importantly, we demonstrate that the combined blockade of TNF-a and IL-17A is more efficient than inhibition of either factor alone. Our results suggest the IgG-like anti-TNF-a/IL-17A bispecific molecule overcome the limited therapeutic responses using anti-TNF drugs. It may be a promising therapeutic agent for the treatment of autoimmune diseases.

\section{INTRODUCTION}

Currently, the pathogenesis of autoimmune disorders is not fully understood. Immune dysfunction is involved in complicated genetic and environmental factors [1]. Over the past decade, monoclonal antibody (mAb) drugs succeed in treatment of autoimmune diseases [2]. These mAbs have benefited millions of patients with chronic diseases, such as rheumatoid arthritis (RA), psoriasis and Crohn's disease, and so on.

Tumor necrosis factor alpha (TNF- $\alpha$ ) is a potent inductor of the inflammatory response in innate immune response [3]. Anti-TNF- $\alpha$ mAbs are undoubtedly to be clinically efficacious for autoimmune diseases, especially for RA. [4]. Despite given the profound therapeutic potential of anti-TNF- $\alpha$ drugs, around $30 \%$ of patients are refractory to anti-TNF- $\alpha$ drugs, responses are frequently considered partial in patients who respond. The interaction of TNF- $\alpha$ receptor (TNF- $\alpha$ R) and TNF- $\alpha$ activates two signal pathways: IKK/NF- $\mathrm{KB}$ and MAPK/AP-1 pathways. Activated pathways, in turn, trigger the production of inflammatory cytokines and chemokines. These TNFinduced cytokines are involved in the initiation and progression of inflammatory diseases. Recent studies indicate that there exists a shared cytokine framework, including TNF- $\alpha$, interleukin (IL)-1, IL-6, IL-17 and IL- 
23 , in certain inflammatory diseases [5]. TNF- $\alpha$ correlates to promote either chemokines (such as IL-8 and monocyte chemotactic protein 1) or angiogenesis [3]. Blockage of IL-1, IL-6, IL-17, or IL-23 has shown clinical efficacy in RA patients [6].

IL-17 is one of main inflammatory cytokines that are secreted by the Th17 T helper cell subset. It is an important contributor to the pathogenesis of autoimmune diseases including RA [7]. When IL-17 binds to its receptor, the activation of NF- $\mathrm{KB}$ and MAPKs signaling pathways are subsequently induced. The IL-17 signaling contributes to the inflammatory response that causes cartilage destruction [8]. IL-17 plays a key role in inducing the production of TNF- $\alpha$ or other pro-inflammatory cytokines in synovial cells and chondrocytes of RA patients [9]. Anti-IL-17 treatment is effective in reducing the onset of clinical arthritis symptoms [10]. Dual inhibition of IL- $1 \alpha / \beta$ [11], IL-1 $\beta / \mathrm{IL}-17$ [12], TNF- $\alpha / \mathrm{IL}-17$ [13, 14], TNF- $\alpha / \mathrm{IL}-$ 6R [15] or TNF- $\alpha$ /Angiopoietin2 [16] is more potent than single targeting for the treatment of RA and other inflammatory disorders.

Bispecific antibodies (bsAbs) binding two different antigens can overcome limitations of monotherapies due to their beneficial characteristics [17-20]. However, the most formats of bsAb, such as or dual-variable domain (DVD) IgG, may result in the potential immunogenicity because of incorporated artificial linkers. Other factors, such as low expression, poor stability, poor affinity and poor biocompatibility, frequently hinder the pharmaceutical development of bsAbs [21]. Here, we generated a stable IgG-like bsAb which kept the properties of intact IgG molecules. This bsAb has not only functional characteristics of the anti-TNF- $\alpha$ antibody, but also additional activity that neutralizes IL-17A. It significantly suppressed the inflammatory cytokine response by simultaneously neutralizing TNF- $\alpha$ and IL-17A in RA models. These studies support that combination therapies for the treatment of RA or other inflammatory disorder are highly promising approaches.

\section{RESULTS}

\section{Generation of the native-like bsAb through electrostatic Fc pairing}

To generate a native-like bispecific molecule, it was built based on a $1+1$ of two half IgG. Heterogenous heavy chain (HC) $\mathrm{Fc}$ regions were paired through electrostatic steering effects. As shown in Figure 1A, two pairs of oppositely charged residues (K392-D399 and D399-K409) are used in the $\mathrm{CH} 3-\mathrm{CH} 3$ domain. The mutations of K409D and K392D in the first Fc, D399K and $\mathrm{E} 356 \mathrm{~K}$ in the second $\mathrm{Fc}$ resulted in the pairing of two heterogenous heavy chains by altering the polarity. The correct association of the light chain and their cognate heavy chains was achieved by exchanging the variable heavy (VH) and the variable light (VL) domains within the anti-IL-17A antibody.

Co-transfection of HEK293 suspension cells with expression vectors encoding the anti-TNF- $\alpha /$ IL-17A bsAb resulted in the production of soluble proteins with the high purity in SDS-PAGE assays (Figure 1B). Yields of anti-TNF- $\alpha$ mAb and bsAb were almost the same $(\sim 7.6$ $\mathrm{mg} / \mathrm{L}$ ), and the yield of anti-IL-17A mAb was about 10 $\mathrm{mg} / \mathrm{L}$ (Supplementary Table S1). Because of exchange of the $\mathrm{VH}$ and $\mathrm{VL}$ in bsAb, one of the light chain of the antibody migrated to a position corresponding to a higher molecular weight. The thermal stability of bsAb was compared with that of the parental mAbs. As shown in Figure 1C, the melting temperature $(\mathrm{Tm})$ of bsAb was lower than that of anti-IL-17A $\mathrm{mAb}\left(\mathrm{Tm}=78^{\circ} \mathrm{C}\right)$, but is equivalent to that of the anti-TNF- $\alpha \mathrm{mAb}(\mathrm{Tm}=$ $68^{\circ} \mathrm{C}$ ). Purities of the antibodies were analyzed by a size exclusion chromatography column (SEC) (Figure 1D). Monomer portions of the anti-TNF- $\alpha$ antibody, anti-IL17A antibody, and bsAb were $86.8 \%, 90.2 \%$, and $96.4 \%$, respectively. These data suggest that the generated bsAb through $\mathrm{Fc}$ heterodimerization retain physical properties of parental mAbs.

\section{Binding abilities of bsAb to TNF- $\alpha$ and IL-17A}

The binding of bsAb to TNF- $\alpha$ and IL-17A was measured by ELISA. As shown in Figure 2A and 2B, EC50 values of bsAb binding to IL-17A and TNF- $\alpha$ were comparable to parental anti-IL-17A and anti-TNF- $\alpha$ $m A b s$. The specificity of bsAb was detected against seven antigens, including TNF- $\alpha$, IL-17A, insulin, IL-2, insulinlike growth factor (IGF)-I, IGF-II, and Interferon (INF)- $\gamma$ by ELISA. BsAb bound to targets TNF- $\alpha$ and IL-17A, but not other irrelevant antigens (Figure 2C).

Surface plasmon resonance (SPR) demonstrated the functionality of both binding moieties toward the respective antigens. To measure the binding kinetics of antibodies to corresponding ligands, TNF- $\alpha$, IL-17A or their mixture with different concentrations was flowed over fixed antibodies on a CM5 chip via an anti-human Fc antibody. SPR sensorgrams were presented in Figure 3. The kinetics values of all antibodies were summarized in Table 1. The calculated association rate constant (kon: 4.7 $\left.\times 10^{5}(\mathrm{~mol} / \mathrm{L})^{-1} \mathrm{~s}^{-1}\right)$ and the dissociation rate constant (koff: $\left.1.6 \times 10^{-5} \mathrm{~s}^{-1}\right)$ of bsAb binding to TNF- $\alpha$ were similar to that of anti-TNF- $\alpha$ antibody (kon: $4.7 \times 10^{5}(\mathrm{~mol} / \mathrm{L})^{-1} \mathrm{~s}^{-1}$, koff: $\left.1.7 \times 10^{-5} \mathrm{~s}^{-1}\right)$. Similarly, the binding affinity of bsAb to TNF- $\alpha\left(\mathrm{K}_{\mathrm{D}}: 0.33 \mathrm{nmol} / \mathrm{L}\right)$ was comparable to that of anti-TNF- $\alpha$ antibody $\left(\mathrm{K}_{\mathrm{D}}: 0.37 \mathrm{nmol} / \mathrm{L}\right)$. BsAb bound to immobilized IL-17A with a high affinity $\left(\mathrm{K}_{\mathrm{D}}: 0.2 \mathrm{nmol} / \mathrm{L}\right)$, which is similar to anti-IL-17A antibody $\left(\mathrm{K}_{\mathrm{D}}: 0.17\right.$ $\mathrm{nmol} / \mathrm{L}$ ). Simultaneous binding to IL-17A and TNF- $\alpha$ was 
also shown. A mixture of TNF- $\alpha$ and IL-17A was used to flow over to determine maximum responses. The Rmax/ capture of bsAb to the mixture was apparently higher than that of parental mAbs. It suggests that a bivalent bsAb could enhance avidity effects better than monovalent reagent.
Neutralization of TNF- $\alpha$-mediated cellular cytotoxicity by bsAb

Fibroblast L929 cell line has been used for the standard analysis of TNF- $\alpha$ cytotoxicity [22]. We employed assays to assess the ability to prevent TNF- $\alpha$ mediated cell cytotoxicity. BsAb inhibited TNF- $\alpha$-induced

A

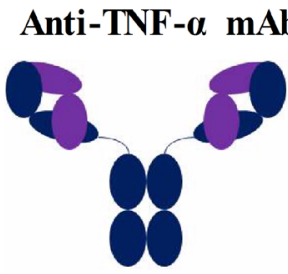

Anti-IL-17A mAb

C
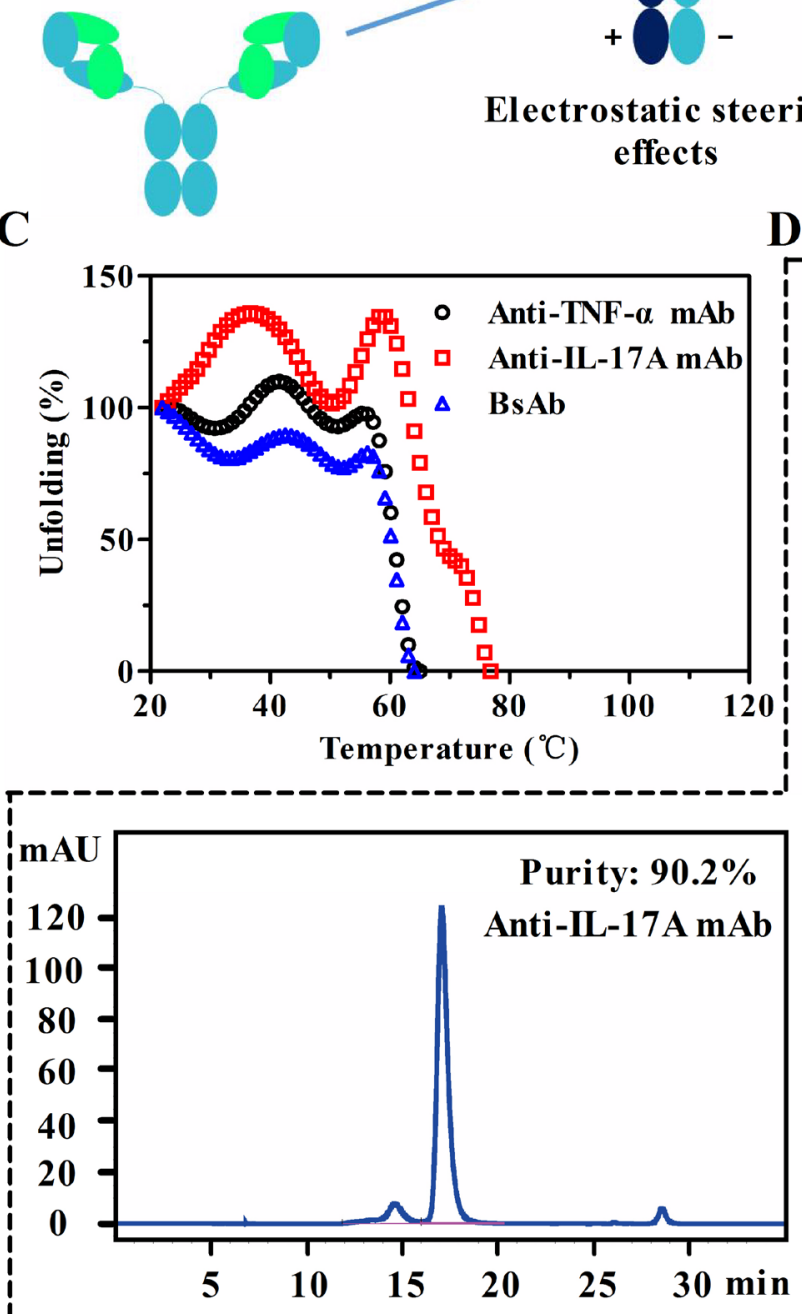

D
B
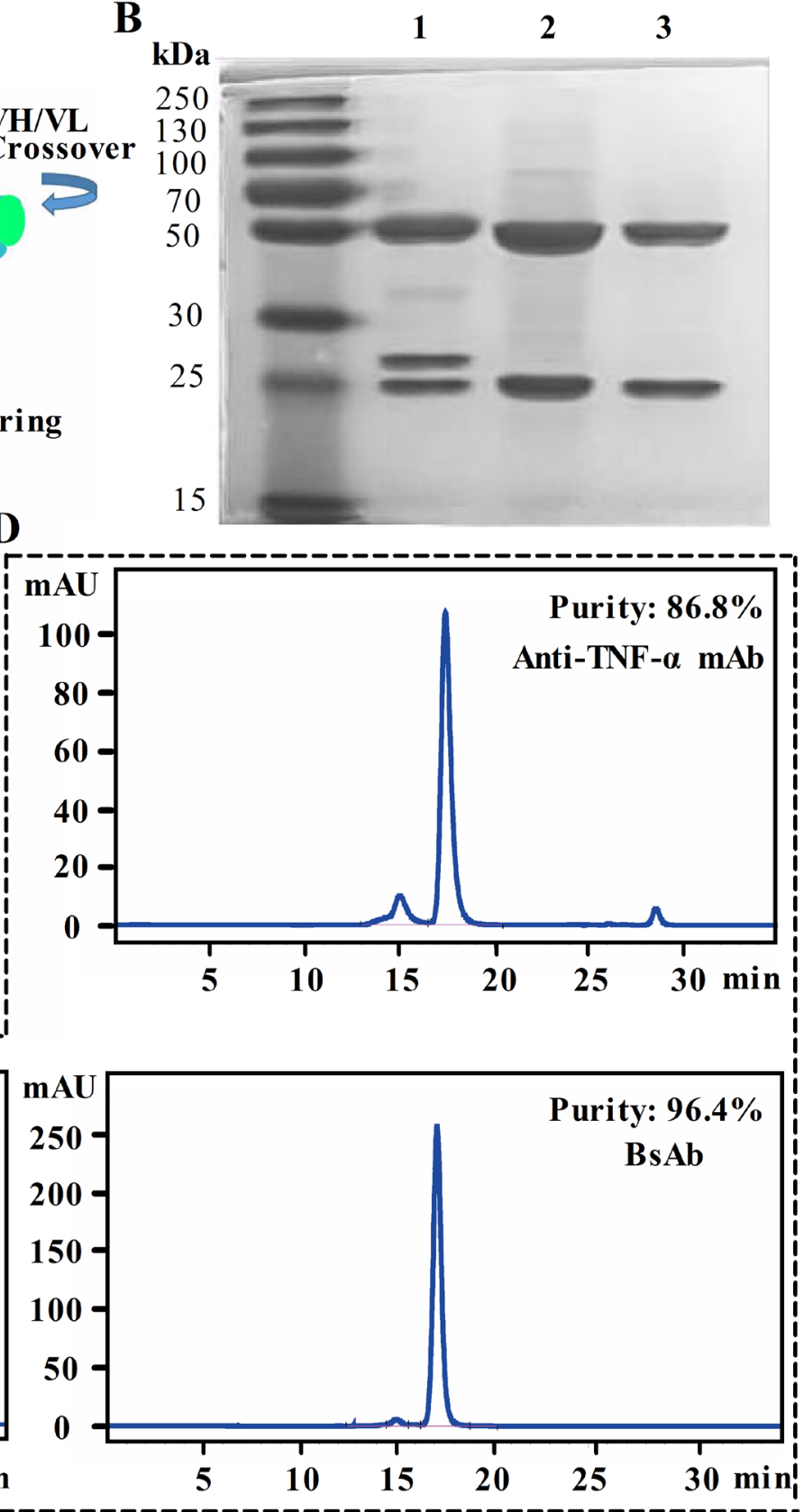

Figure 1: Generation and characterization of anti-TNF-a/IL-17A bispecific antibody (bsAb). A. Schematic diagram of bsAb generated by fusion of anti-TNF- $\alpha$ antibody and anti-IL-17A antibody. BsAb consists of a crossed anti-IL-17A arm (CH1-C exchange) and an uncrossed anti-TNF- $\alpha$ arm. The parental monoclonal antibodies (mAb) are shown on the left. Fc parts of heavy chains are paired through an electrostatic steering effects. B. SDS-PAGE analysis of purified bsAb (lane 1), anti-IL-17A mAb (lane 2), and anti-TNF- $\alpha$ mAb (lane 3). C. Comparison of thermal stability of three antibodies by circular dichroism. D. The purity analysis of bsAb and parental mAbs by a size exclusion chromatography column. 

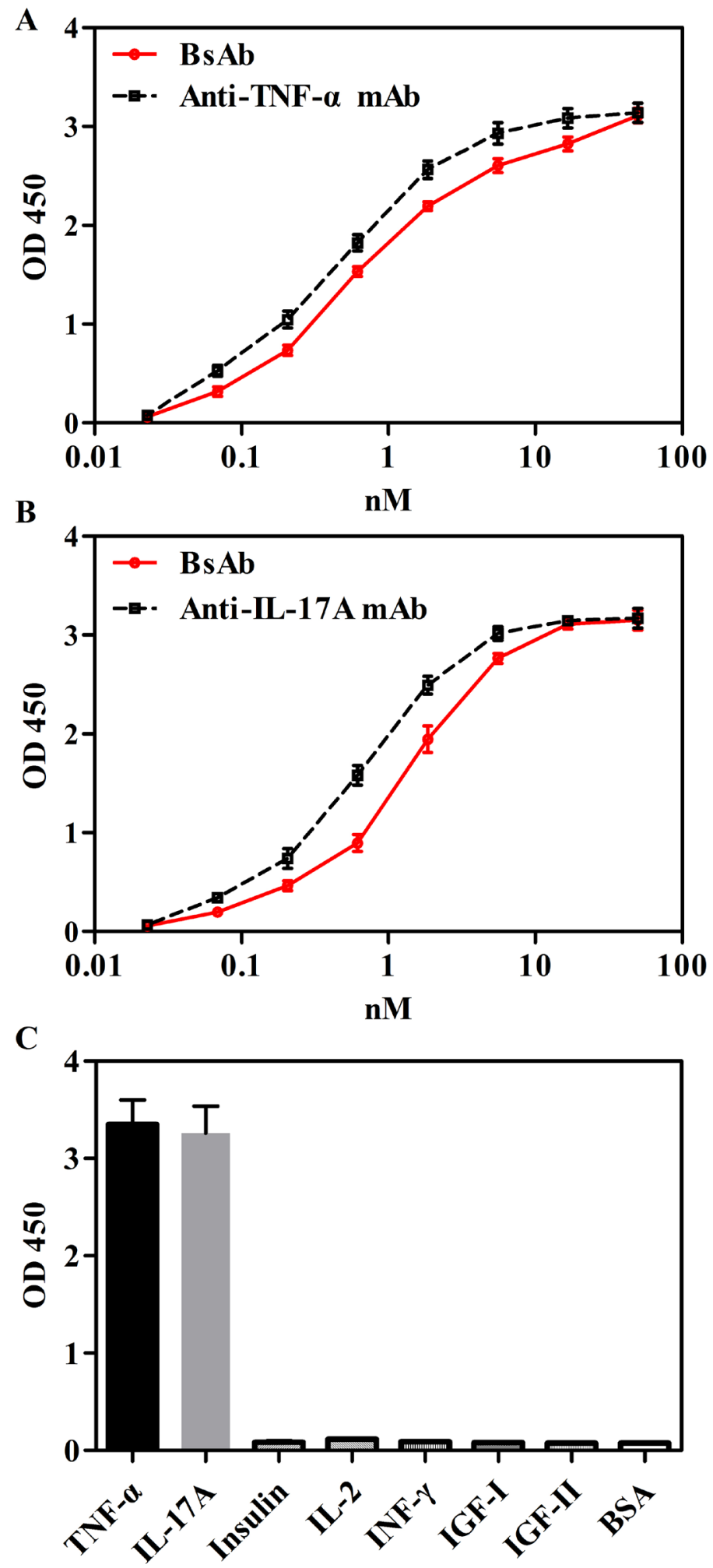

Figure 2: Binding abilities of bsAb to TNF- $\alpha$ and IL-17A in ELISA. A. Immobilized TNF- $\alpha$ was bound with anti-TNF- $\alpha$ mAb or bsAb with serial dilutions. B. Immobilized IL-17A was bound with anti-IL-17A mAb or bsAb with serial dilutions. C. Specificity of bsAb were measure by detecting seven antigens, including TNF- $\alpha$, IL-17A, insulin, IL-2, IGF-I, IGF-II, and INF- $\gamma$. Bound antibodies were detected with a horseradish peroxidase-conjugated anti-human Fc antibody and measured as optical densities (OD) at 450nm.The data are a representative of 3 separate experiments. 
L929 cell cytotoxicity in a dose-dependent manner, which was comparable to that of anti-TNF- $\alpha$ mAb (Figure 4). Anti-IL-17A mAb and control anti-IGF-I/II mAb m708.5 had no effect on neutralization of TNF- $\alpha$.

\section{Addition and synergy of combined IL-17A and TNF- $\alpha$ to induce the inflammatory cytokine responses on FLS}

FLS is a crucial resident cell type involved in RA pathogenesis. Here, we investigated the production of key inflammatory cytokines in RA-FLS after cotreatment with IL-17A and TNF- $\alpha$. When RA-FLS cells were incubated with IL-17A, TNF- $\alpha$, or both, mRNA expressions of IL- 6 and IL- 8 were assessed. In addition, secretions of cytokines (IL-6 and IL-8) in culture media were measured by ELISA. Combination of IL-17A and TNF- $\alpha$ significantly resulted in additive or synergistic increase of IL-6 and IL-8 expressions (Figure 5). Thus, IL-17A appears to exert an additive and synergistic effect with TNF- $\alpha$ on FLS. The above results suggest that FLS is an effective model to assess combined blockade of bsAbs in next studies.

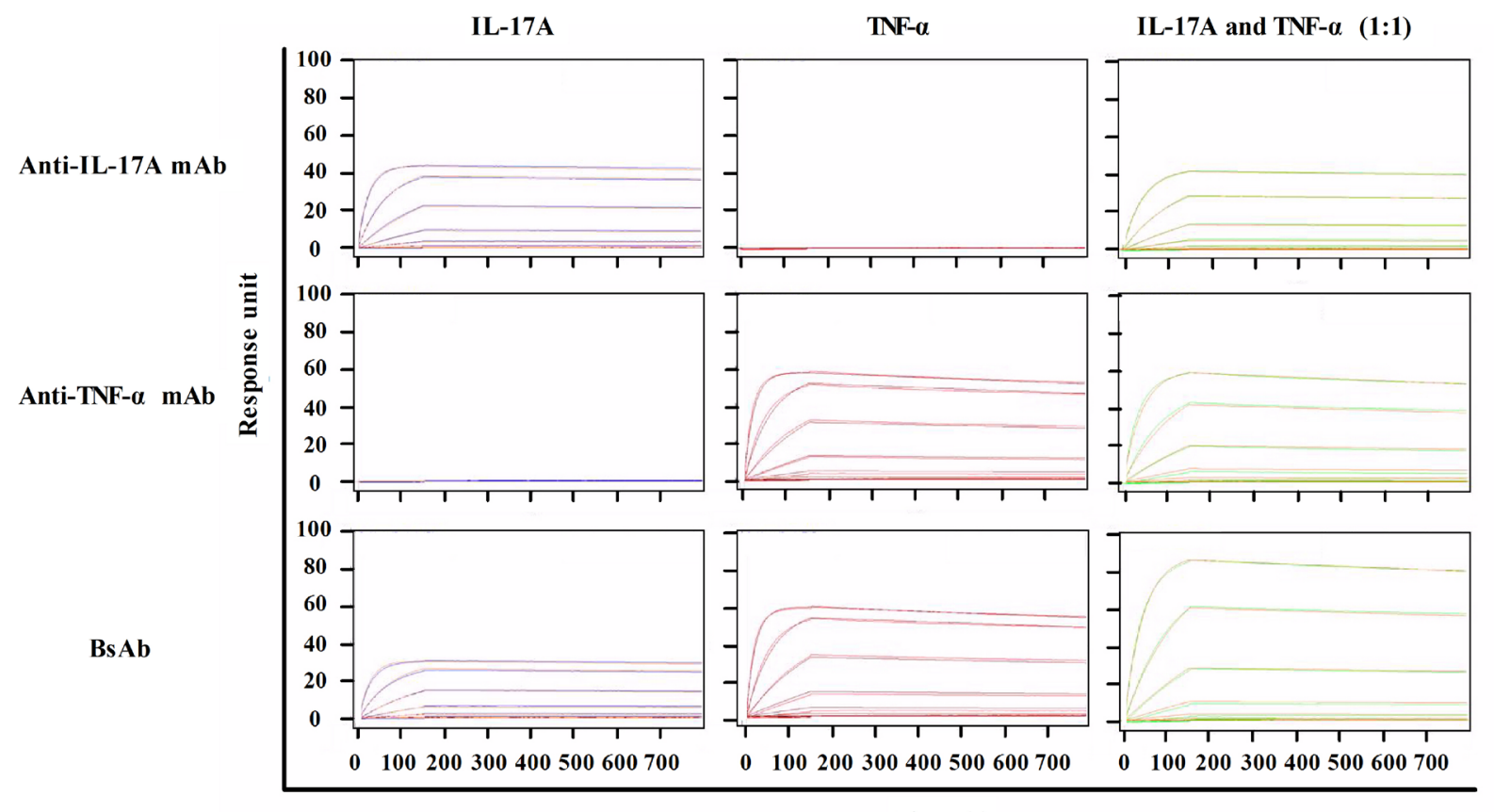

Time (s)

Figure 3: SPR analysis of antibodies against TNF- $\alpha$ and IL-17A. Anti-IL-17A mAb, ant-TNF- $\alpha$ mAb, or bispecific antibody was captured by anti-human Fc antibody on to a CM5 chip. A range of TNF- $\alpha(0 \mathrm{nM}$ to $100 \mathrm{nM})$ and IL-17A ( $0 \mathrm{nM}$ to $100 \mathrm{nM})$ were injected over all antibodies. Data was fitted to a 1:1 Langmuir binding model to determine binding parameters.

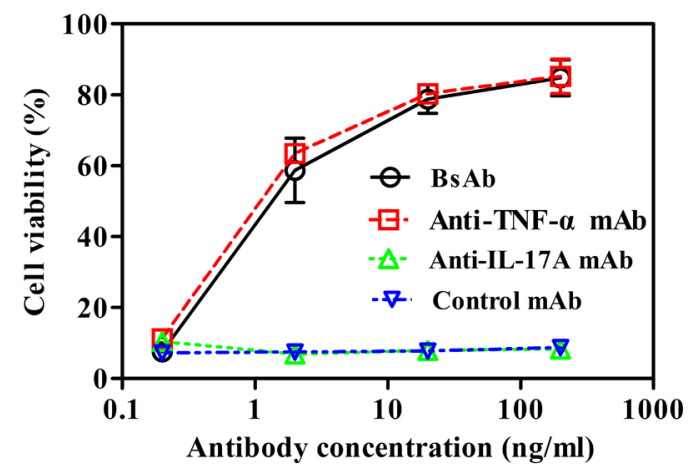

Figure 4: Neutralization of TNF- $\alpha$-mediated cellular cytotoxicity by bsAb. L929 cells were incubated with $1 \mathrm{ng} / \mathrm{ml}$ of TNF- $\alpha$ and $4 \mu \mathrm{g} / \mathrm{ml}$ of actinomycin D. Then, cells were treated with various concentrations of bsAb, anti-TNF $\alpha \mathrm{mAb}$, anti-IL-17A mAb and antiIGF-I/II mAb m708.5 as a control antibody. After $24 \mathrm{~h}$, cell viabilities were determined by MTT method. The error bars represent mean \pm SEM. Data shown are representatives of three independent experiments. 
Inhibition of bsAb on the production of neutrophil and Th17 chemokines on FLS

Neutrophil recruitment can be promoted in inflammation sites through FLS activation by IL-17A and TNF- $\alpha[23,24]$. Gene expression levels of mediator cytokines were very low when IL-17A and TNF- $\alpha$ were used alone, but combination of two cytokines synergistically increased chemokine expression. We evaluated the inhibitory effects of bsAb on the production of inflammatory mediators on FLS. The mRNA and protein expressions of neutrophil chemokines (CXCL1, CXCL2, CXCL6) and the Th17 chemokine (CCL20) were significantly decreased when both IL-17A and TNF- $\alpha$ were blocked (Figure 6). BsAb showed a superior effect to single treatment and comparable of the combination of two mAbs. Our results suggest that blocking two antigens simultaneously is better than inhibition of solo antigen.

\section{Inhibition of inflammatory cytokine responses in RA-FLS by bsAb against TNF- $\alpha$ and IL-17A}

The gene levels of IL- 6 and IL-8 were examined in FLS from RA patients after FLS were treated with antibodies (Figure 7A). Anti-TNF- $\alpha$ or anti-IL-17A mAbs had effects to prevent cytokine induction in FLS stimulated with both cytokines in the mRNA level. BsAb
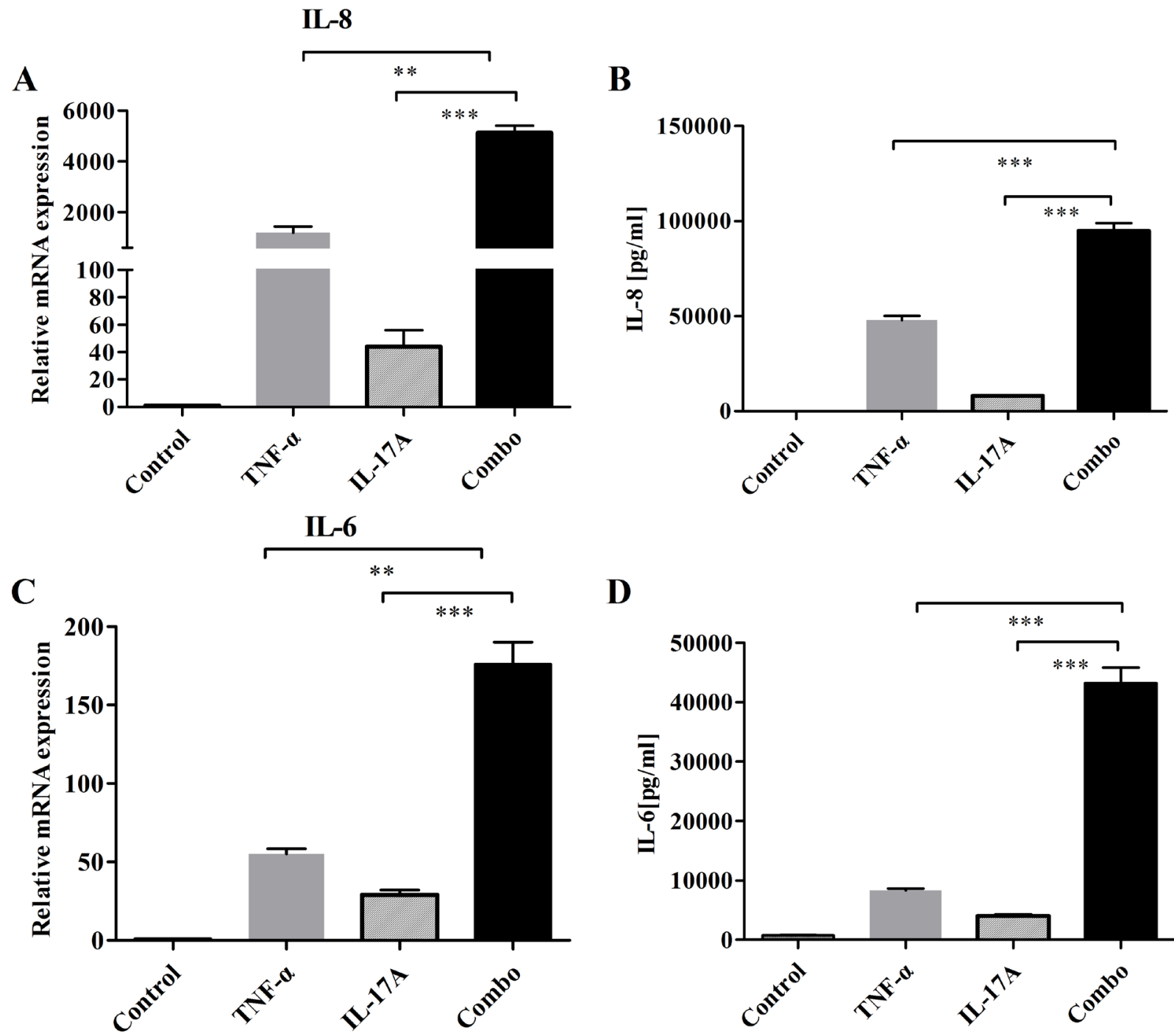

D

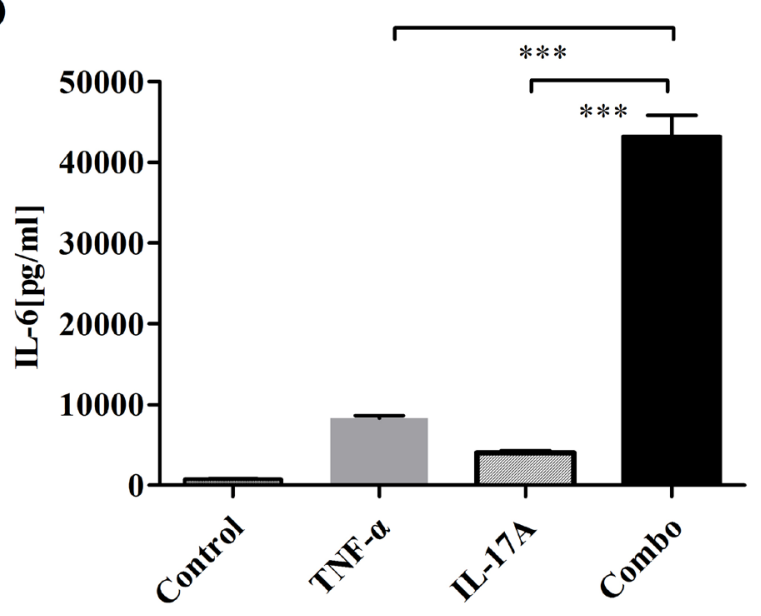

Figure 5: Addition and synergy of combined IL-17 and TNF- $\alpha$ to induce the production of IL-6 and IL-8 on FLS. A. After cells were stimulated with IL-17 and TNF- $\alpha$ for $12 \mathrm{~h}$, mRNA expressions of cytokines (IL-6, IL-8) were determined by realtimePCR. B. Secretions of cytokines (IL-6 and IL-8) in culture media were measured by ELISA. All results are representative of at least three independent experiments. 
A
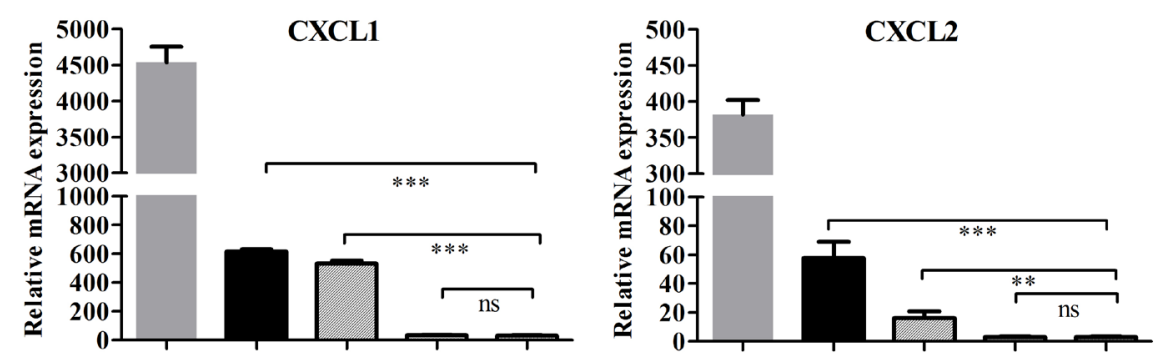

B
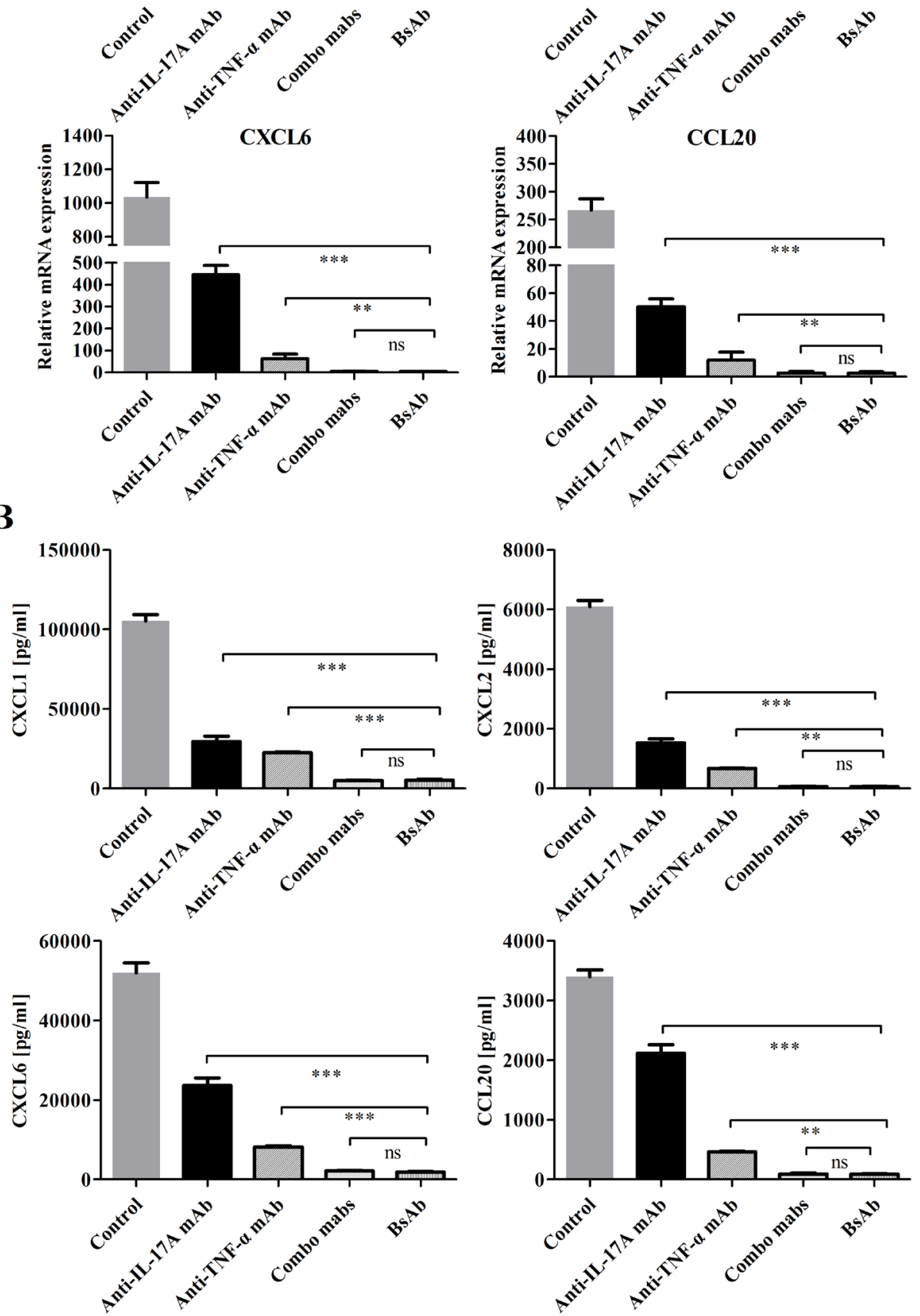

Figure 6: Inhibition of bsAb on the production of neutrophil and Th17 chemokines on FLS. A. FLS cells were incubated with IL-17 and TNF- $\alpha$ or in the presence of different, antibodies. The mRNA expression levels of CXCL1, CXCL2, CXCL6, and CCL20 were measured by realtime-PCR after stimulation for $12 \mathrm{~h}$. B. After FLS were treated, the secretion of chemokines from RA-FLS were measured by ELISA. All results are representative of at least three independent experiments. 
A

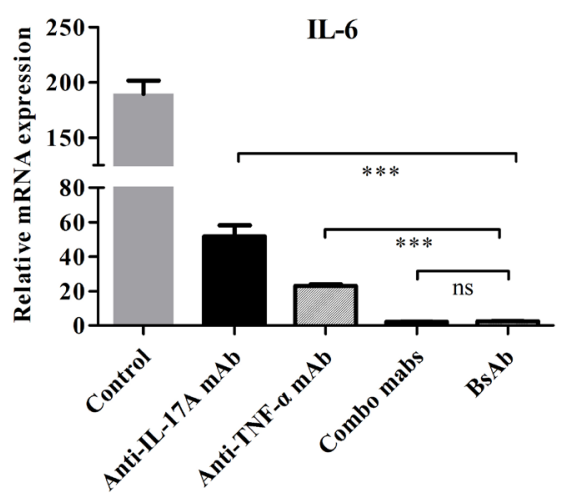

B

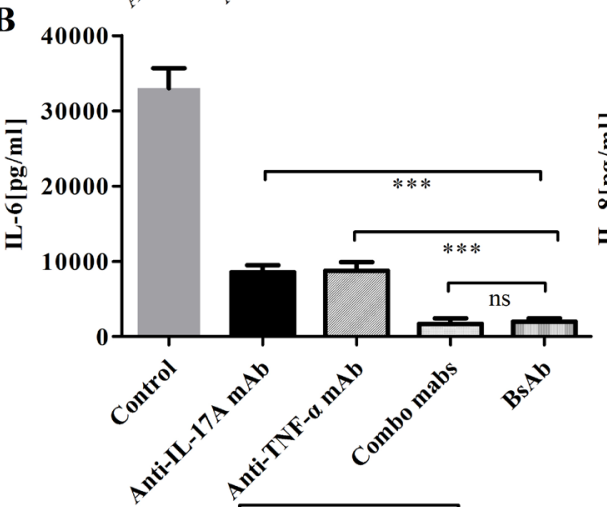

C
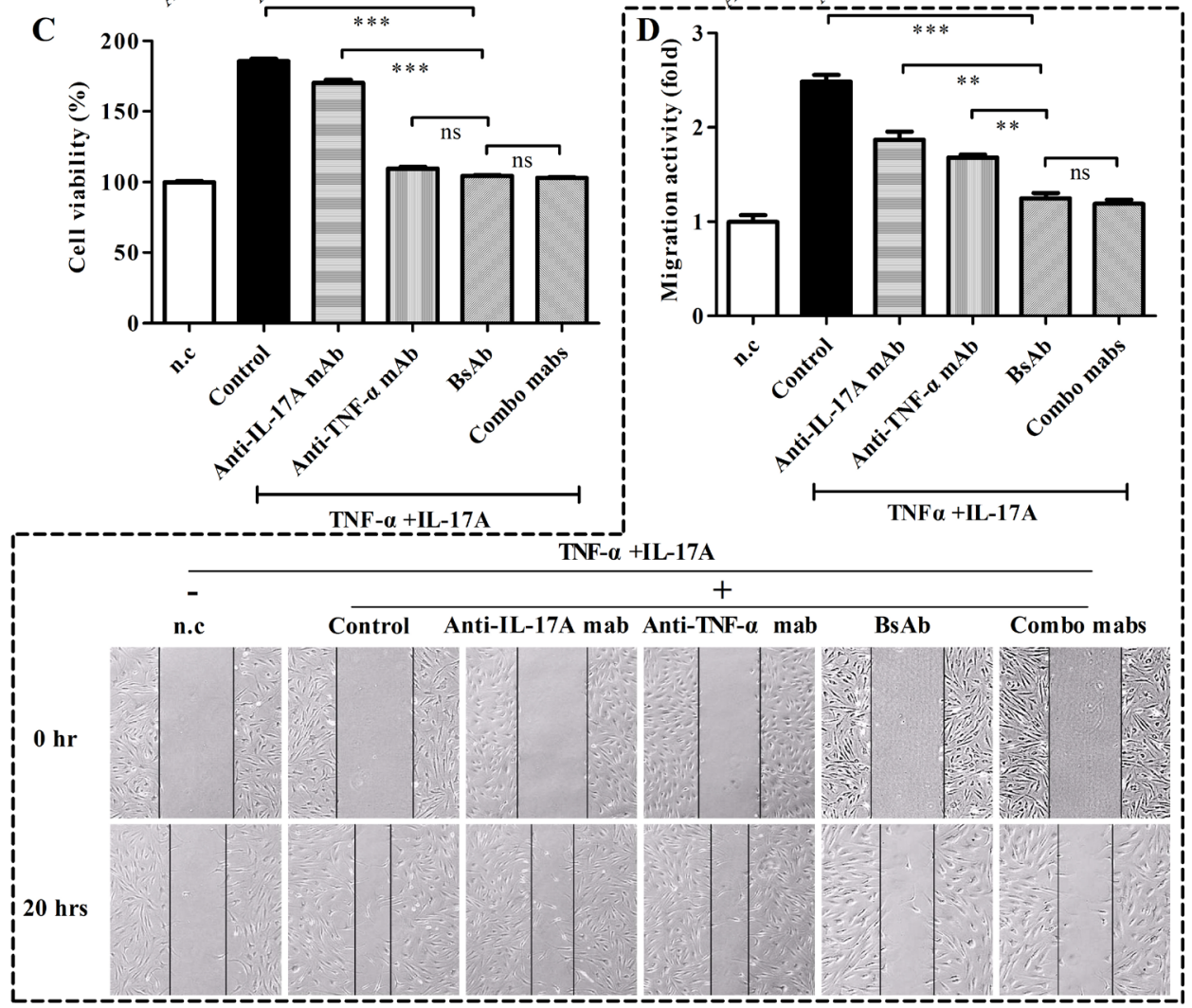

Figure 7: Inhibition of bsAb on the production of IL-6 and IL- 8 and proliferation, and migration of FLS. FLS cells were stimulated with TNF- $\alpha$ and IL-17A or in the presence of different, antibodies. A. The mRNA levels of IL-6 and IL- 8 were determined by realtime-PCR. B. Secretions of cytokines (IL-6 and IL-8) in culture media were measured by ELISA. C. Anti-proliferative effects of bsAb on FLS. After FLS cells were incubated with TNF- $\alpha$ and IL-17A, antibodies was added during the incubation. Cell proliferation was assessed using MTT assay. D. The anti-migration effects of bsAb on FLS were evaluated by the scratch assay. After wounds were formed, FLS were incubated with antibodies in the presence of TNF- $\alpha$ and IL-17A. Parallel lines represent the borders of the wounds. 
Table 1: SPR summary of anti-TNF- $\alpha /$ IL-17A bsAb, anti-TNF- $\alpha$ mAb and anti-IL-17A mAb.

\begin{tabular}{|c|c|c|c|c|c|}
\hline Antibody & Antigen & kon, $\left(\mathrm{mol} / \mathrm{L}^{-1}\right) \mathrm{s}^{-1}$ & koff, $\mathbf{s}^{-1}$ & $\operatorname{Rmax}$ & $\mathrm{K}_{\mathrm{D}}, \mathrm{mol} / \mathrm{L}$ \\
\hline \multirow[b]{3}{*}{ Anti-IL-17A mAb } & IL-17A & $4.2 \times 10^{5}$ & $7.0 \times 10^{-5}$ & 43.6 & $1.7 \times 10^{-10}$ \\
\hline & TNF- $\alpha$ & No Binding & & & \\
\hline & IL-17A+TNF- $\alpha$ & $4.4 \times 10^{5}$ & $7.5 \times 10^{-5}$ & 43.1 & $1.7 \times 10^{-10}$ \\
\hline \multirow{3}{*}{ Anti-TNF- $\alpha$ mAb } & IL-17A & No binding & & & \\
\hline & TNF- $\alpha$ & $4.7 \times 10^{5}$ & $1.7 \times 10^{-4}$ & 57.8 & $3.7 \times 10^{-10}$ \\
\hline & IL-17A+TNF- $\alpha$ & $4.7 \times 10^{5}$ & $1.7 \times 10^{-4}$ & 60.3 & $3.7 \times 10^{-10}$ \\
\hline \multirow{3}{*}{$\mathrm{BsAb}$} & IL-17A & $4.0 \times 10^{5}$ & $7.9 \times 10^{-5}$ & 30.6 & $2.0 \times 10^{-10}$ \\
\hline & TNF- $\alpha$ & $4.7 \times 10^{5}$ & $1.6 \times 10^{-4}$ & 59.1 & $3.3 \times 10^{-10}$ \\
\hline & IL-17A+TNF- $\alpha$ & $4.6 \times 10^{5}$ & $1.2 \times 10^{-4}$ & 88.6 & $2.5 \times 10^{-10}$ \\
\hline
\end{tabular}

showed superior inhibitory effects than single $\mathrm{mAb}$ treatments. Meanwhile, we detected the secretion levels of IL-6 and IL-8 in cell supernatants by ELISA (Figure 7B). Consistent results were seen after treatment with bs $\mathrm{Ab}$ or combination of two mAbs. The secretion of IL- 6 and IL- 8 was significantly decreased by bsAb. Thus, dual blockage of TNF- $\alpha$ and IL-17A cytokines could sustain relatively low levels of IL-6 and IL-8 responses.

\section{Anti-proliferative and anti-migration effect of bsAb on FLS}

The anti-proliferative effects of bsAb were analyzed on FLS in vitro. BsAb and anti-TNF- $\alpha$ mAb inhibited the proliferation of FLS whereas anti-17A mAb did not (Figure 7C). We predict that TNF- $\alpha$ is a key contributor for the proliferation of synoviocytes. Because TNF- $\alpha$ and IL-17 are both involved in the migration of fibroblasts [25], the scratch assay could be used to examine the antimigration function of the bsAb. The co-treatment of IL$17 \mathrm{~A}$ and TNF- $\alpha$ significantly increased the cell migration activity. All antibodies could inhibit the migration of RAFLS in different degrees. The migration activity of FLS cells appeared to be the lowest when both the antigens were blocked by bsAb simultaneously (Figure 7D).

\section{DISCUSSION}

Though TNF- $\alpha$ and IL-17A are independently involved in pathophysiology of RA, elevated IL-17 and TNF- $\alpha$ appear in the synovium of RA patients [26]. They act in synergy as inducing mediators of inflammation in fibroblast-like synoviocytes. Combined blockade of TNF- $\alpha$ and IL-17A pathways results in decrease of arthritic symptoms in patients who fail to respond to single-cytokine inhibition [27]. Inhibitions are believed to be selective because normal immunity would be not interfered.

We generated a native-like bsAb through a combination method of electrostatic Fc pairing and light chain crossover. It is different with other reported anti$\mathrm{TNF} / \mathrm{IL}-17 \mathrm{~A}$ bsAbs. BsAb is based on fully human antiTNF- $\alpha$ and IL-17A antibodies. The electrostatic pairing results in less mismatching of heavy chains than the knobinto-hole pairing. Mismatched heavy or light chains are main problems during the production of IgG-like bsAbs. Importantly, it aborts to use any artificial linkers that induce possible secondary adverse effects in body. In SPR assay, bsAb showed high-affinities to human TNF- $\alpha$ and IL-17A. It partially bound to mouse TNF- $\alpha$ and did not respond to mouse IL-17A (Supplementary Figure S1). It is still challenging to test bioactivitie of anti-human IL-17A antibodies in RA mouse models. We observed that bs Ab obviously enhanced response of captured antigens when it bound two antigens. It is a unique feature of bsAb so that soluble polypeptides can be quickly eliminated through the bivalent binding $[18,20]$.

Several crucial factors CXCL1, CXCL2, CXCL5, CXCL6 and IL-8 are involved in the recruitment of neutrophils in inflammation of RA $[15,28]$. Th17 cells are known to contribute to arthritis pathogenesis in some patients treated with anti-TNF drugs [29]. FLS are key effector cells in rheumatoid arthritis. Targeting FLS might improve therapy effects in inflammatory arthritis without inhibiting systemic immunity [30]. Anti-TNF- $\alpha /$ IL-17A bsAb significantly inhibited the expression levels of neutrophil chemokines CXCL1, CXCL2, CXCL6 and the Th17 chemokine secreted by FLS. IL-17A is a major inducer of IL-6 and IL-8 that are key pro-inflammatory cytokines in inflammation and joint damage of RA [31]. We observed that IL- 6 and IL-8 were abundantly secreted by IL-17A- and TNF- $\alpha$-stimulated FLS. The observation is consistent with previous reports $[26,32]$. Though the bsAb showed similar inhibition effects with two monospecific reagents, bsAb would be less costly than two monospecific antibodies and leads to less immunogenic response in patients [33].

In conclusion, we generated a native-like bsAb that has the potential as therapeutic molecules in the treatment of inflammatory diseases. Dual inhibition of TNF- $\alpha /$ IL-17 is efficacious to reduce signaling redundancy in 
rheumatoid arthritis. It is interesting to further investigate the efficacy and safety of bsAb in humanized RA transgenic mouse models.

\section{MATERIALS AND METHODS}

\section{Cells and cell culture}

Fibroblast cell line L929 was purchased from the Type Culture Collection of the Chinese Academy of Sciences, Shanghai, China. Fibroblast-like synoviocytes (FLS) were isolated from synovial tissue of a RA patient. All procedures followed were in accordance with the ethical standards approved by Jilin University. FLS cells were cultured in RPMI1640 medium (Hyclone) containing $10 \% \mathrm{FBS}, 100 \mathrm{U} / \mathrm{ml}$ penicillin, and $100 \mu \mathrm{g} /$ $\mathrm{ml}$ streptomycin. L929 cells were cultured in DMEM medium (Hyclone) containing 10\% fetal bovine serum (FBS) (Hyclone). All the cells used in the experiment were in passage 4 to 10 .

\section{Construction of antibody expression vectors}

Antibody variable region sequences of anti-TNF- $\alpha$ (adalimumab) $\mathrm{mAb}$ and anti-IL-17A (secukinumab) $\mathrm{mAb}$ were used to make $\mathrm{IgG}$ or bsAb expression vectors. As shown in Figure 1A, anti-TNF- $\alpha$ /IL-17A bispecific antibodies were generated based on these antibodies (human IgG1 backbone). The Fc regions of two heavy chains were paired by an electrostatic steering effects methodology [34]. Sequentially, correct association of the light chains and their heavy chains was achieved by exchange of variable heavy $(\mathrm{VH})$ and variable light (VL) domains within the antigen binding fragment $(\mathrm{Fab})$ of antiIL-17A of bsAb. Meanwhile, IgGs of anti-TNF- $\alpha$ and antiIL-17A were made in the same backbone. All genes were synthesized by Genescript.

\section{Expression and purification of antibodies}

Serum-free suspension HEK293 cells (Life Technologies) were used to express bsAb and mAbs. Transfection into HEK293 cells was performed according to the instruction as described previously [19]. Briefly, HEK293 cells were cultivated in FreeStyle ${ }^{\text {TM }} 293$ Expression Medium (Life Technologies). The mixture of expression plasmids at concentration of $10 \mu \mathrm{g} / \mathrm{ml}$ and PEI (25000 MW, Polysciences) at final concentration of $20 \mu \mathrm{g} / \mathrm{ml}$ was prepared in $1 / 10$ volume of fresh culture medium. After incubation for $15 \mathrm{~min}$ at room temperature, the mixture was slowly dropped into cells. After four days of post-transfection, the culture supernatant was harvested. Antibodies were purified from cell culture supernatants by the Protein A Sepharose TM chromatography (GE Healthcare).

\section{Size-exclusion chromatography}

Antibodies were added to a Sepax SRT SEC-500 column (Sepax Technologies Inc.,) respectively. And the composition of the mobile phase was $150 \mathrm{mM}$ sodium phosphate at a $\mathrm{pH}$ of 7.2. The flow rate was $1.0 \mathrm{ml} / \mathrm{min}$ and we used $280 \mathrm{~nm}$ detection wavelength to monitor the eluent.

\section{Circular dichroism}

Far UV circular dichroism spectra were recorded on a Jasco J-815 spectropolarimeter (Jasco International). Antibodies were prepared in $1 \mathrm{ml}$ of $20 \mathrm{mM}$ phosphate buffer containing $0.15 \mathrm{M} \mathrm{NaCl}$ at $\mathrm{pH}$ 7.0. The spectra were analyzed by monitoring the molar ellipticity changes at $222 \mathrm{~nm}$ as a function of temperature increase. The sample was heated at a rate of $10{ }^{\circ} \mathrm{C} / \mathrm{min}$ over a temperature range of $20-80^{\circ} \mathrm{C}$. The normalized ellipticity signal was plotted as a function of temperature to understand changes in thermal stability.

\section{ELISA assay}

TNF- $\alpha$ and IL-17A (Peprotech) were coated on 96-well ELISA plates overnight at $4^{\circ} \mathrm{C}$. Antibodies with different dilutions were incubated for $1 \mathrm{~h}$. Bound antibodies were detected with the secondary anti-human Fc-HRP antibody (1:2,000 dilution; Life Technologies). The 2, 20-azino-bis-(3-ethylbenzthiazoline-6-sulfonic acid) substrate (Sigma) was added and the reaction was read at $450 \mathrm{~nm}$.

\section{Surface plasmon resonance}

Interactions between antibodies and TNF- $\alpha$ and IL-17A were analyzed by SPR technology using a Biacore X100 instrument (GE healthcare). Anti-TNF- $\alpha$ $\mathrm{mAb}$, anti-IL-17A mAb or bsAb was immobilized to the surface of a CM5 sensor chip using the standard aminecoupling chemistry method. For analysis of the kinetics of interactions, varying concentrations of TNF- $\alpha(0 \mathrm{nM}$ to $100 \mathrm{nM}$ at three-fold serial dilutions) IL- $17 \mathrm{~A}(0 \mathrm{nM}$ to $100 \mathrm{nM}$ at three-fold serial dilutions), or a mixture of both TNF- $\alpha$ and IL- $17 \mathrm{~A}(0 \mathrm{nM}$ to $50 \mathrm{nM}$ at three-fold serial dilutions) were injected at flow rate of $30 \mu \mathrm{l} / \mathrm{min}$ using running buffer HBS-EP containing $10 \mathrm{mmol} / \mathrm{L}$ HEPES, $150 \mathrm{mmol} / \mathrm{L} \mathrm{NaCl}, 3 \mathrm{mmol} / \mathrm{L}$ EDTA, and $0.05 \%$ Surfactant $\mathrm{P}-20$ at $\mathrm{pH}$ 7.4. Binding data were analyzed using a $1: 1$ Langmuir model. Langmuir binding model to obtain the association rate constant $(\mathrm{ka})$, dissociation rate constant 
$(\mathrm{kd})$ and the equilibrium dissociation rate constant $\left(\mathrm{K}_{\mathrm{D}}\right)$. All the experiments were done at $25^{\circ} \mathrm{C}$.

\section{Cell cytotoxicity assay}

L929 cells were cultured in 96-well plates at $3.5 \times 10^{4}$ cells/well in $100 \mu 1$ of medium supplemented with $10 \%$ FBS overnight, and then incubated with 1 $\mathrm{ng} / \mathrm{ml} \mathrm{TNF}-\alpha$ plus $4 \mu \mathrm{g} / \mathrm{ml}$ of Actinomycin D in the presence of various concentrations of antibodies for 24 $\mathrm{h}$ at $37^{\circ} \mathrm{C}$. Cell viabilities were determined by adding $10 \mu \mathrm{l}$ of (3-(4,5-dimethyl-2-thiazolyl)-2,5-diphenyl2-H-tetrazolium bromide (Promega). Absorbance was measured at $450 \mathrm{~nm}$ using a Biotek ELISA plate reader.

\section{Real-time PCR}

FLS cells were seeded in 6 -well plates $\left(5 \times 10^{4}\right.$ cells/well), and incubated for two days. After removing medium, cells were incubated with mixtures of TNF- $\alpha$ $(0.5 \mathrm{ng} / \mathrm{ml})$ and $\mathrm{IL}-17 \mathrm{~A}(50 \mathrm{ng} / \mathrm{ml})$. Inhibition assays were performed by adding $100 \mu \mathrm{g} / \mathrm{ml}$ of the single $\mathrm{mAb}$, bsAbs, or the mixture of two mAbs $(50 \mu \mathrm{g} / \mathrm{ml}+50 \mu \mathrm{g} /$ $\mathrm{ml}$ ). After $12 \mathrm{~h}$, total RNA was extracted from cells using the trizol method and then transcribed to complementary DNA using an AffinityScript QPCR cDNA Synthesis Kit (Agilent). Quantitative PCR was performed using an Mx3000P Real-Time PCR System (Agilent). The resulting amplification and melting curves were analyzed to ensure specific PCR product. Ct values were used to calculate the fold change in transcript levels.

\section{Detection of cytokines and chemokines by ELISA}

FLS cells were seeded in 6 -well plates $\left(5 \times 10^{4}\right.$ cells/well), and the plates were cultured for two days. After removing medium, cells were incubated with mixtures of TNF- $\alpha(0.5 \mathrm{ng} / \mathrm{ml})$ and IL-17A $(50 \mathrm{ng} / \mathrm{ml})$. Inhibition assays were performed by $100 \mu \mathrm{g} / \mathrm{ml}$ of the single $\mathrm{mAb}$, bsAbs, or the mixture of two mAbs $(50 \mu \mathrm{g} /$ $\mathrm{ml}+50 \mu \mathrm{g} / \mathrm{ml}$ ). After $24 \mathrm{~h}$, the secreted IL- 6 and IL- 8 in culture supernatants were measured using ELISA kits (eBioscience) according to the manufacturers' instructions.

\section{Cell proliferation assay}

FLS cells were incubated with or without IL-17A (100 ng/ml), and human TNF- $\alpha$ (20 ng/ml) for $48 \mathrm{~h}$. During the incubation, cells were treated with $100 \mu \mathrm{g} / \mathrm{ml}$ of the single $\mathrm{mAb}$, bsAbs, or the mixture of two mAbs $(50 \mu \mathrm{g} /$ $\mathrm{ml}+50 \mu \mathrm{g} / \mathrm{ml}$ ). FLS were also cultured without cytokines and antibodies as a negative control. Cell viabilities were determined by adding $10 \mu \mathrm{l}$ of (3-(4,5-dimethyl-
2-thiazolyl)-2,5-diphenyl-2-H-tetrazolium bromide (Promega). Absorbance was measured at $450 \mathrm{~nm}$ using a Biotek ELISA plate reader.

\section{Scratch assay}

FLS cells were seeded in 6 -well plates $\left(5 \times 10^{4}\right.$ cells/ well). When the confluence of FLS reached $100 \%$, the cell layer was scratched with a pipette tip. After washed with medium, the cells were cultured with fresh medium. The mixture of TNF- $\alpha(20 \mathrm{ng} / \mathrm{ml})$ and IL-17A (200 ng/ ml) were added to cell wells. During the cell culture, FLS cells were treated with $100 \mu \mathrm{g} / \mathrm{ml} \mathrm{mAb}$, bsAbs or the mixture of the two mAbs $(50 \mu \mathrm{g} / \mathrm{ml}+50 \mu \mathrm{g} / \mathrm{ml})$. The images were acquired by inverted microscope at 0 and $20 \mathrm{~h}$. The migration activities were calculated as follows: migration activity $=1-($ wounded area at $20 \mathrm{~h}) /($ wounded area at $0 \mathrm{~h}$ ).

\section{Statistical analysis}

Mean \pm SE values were calculated, and the significance of differences was calculated using the Prism Graphpad software. $P$ values less than 0.05 were considered significant.

\section{Abbreviations}

tumor necrosis factor (TNF), rheumatoid arthritis (RA), bispecific antibodiy (bsAb), fibroblast-like synoviocytes (FLS), monoclonal antibody (mAb), TNF- $\alpha$ receptor (TNF- $\alpha$ R), dual-variable domain (DVD), heavy chain $(\mathrm{HC})$, variable heavy $(\mathrm{VH})$, variable light $(\mathrm{VL})$, size exclusion chromatography column (SEC), Surface plasmon resonance (SPR), fetal bovine serum (FBS), melting temperature $(\mathrm{Tm})$.

\section{ACKNOWLEDGMENTS}

We appreciate the support of Zhizhen Chen in University of Macau and Dr. Dezhi Li in Shenzhen iStem Regenerative Medicine.

\section{CONFLICTS OF INTEREST}

All authors have no potential conflicts of interest.

\section{FUNDING}

This work was supported by the Guangdong Science and Technology Program (2016A050502034), Natural Science Foundation of Guangdong (Grand No. 2015A030313741), National Natural Science Foundation 
of China (31570936; 31440041), Macau Science and Technology Development Fund (131/2016/A3), and Startup Research Grant of University of Macau (SRG201600082-FHS).

\section{REFERENCES}

1. Gregersen PK, Behrens TW. Genetics of autoimmune diseases--disorders of immune homeostasis. Nat Rev Genet. 2006; 7: 917-28. doi: 10.1038/nrg1944.

2. Denmark VK, Mayer L. Current status of monoclonal antibody therapy for the treatment of inflammatory bowel disease: an update. Expert Rev Clin Immunol. 2013; 9: 7792. doi: 10.1586/eci.12.91.

3. Silva LC, Ortigosa LC, Benard G. Anti-TNF-alpha agents in the treatment of immune-mediated inflammatory diseases: mechanisms of action and pitfalls. Immunotherapy. 2010; 2: 817-33. doi: 10.2217/imt.10.67.

4. Tansey MG, Szymkowski DE. The TNF superfamily in 2009: new pathways, new indications, and new drugs. Drug Discov Today. 2009; 14: 1082-8. doi: 10.1016/j. drudis.2009.10.002.

5. Schett G, Elewaut D, McInnes IB, Dayer JM, Neurath MF. How cytokine networks fuel inflammation: Toward a cytokine-based disease taxonomy. Nat Med. 2013; 19: 8224. doi: $10.1038 / \mathrm{nm} .3260$.

6. Siebert S, Tsoukas A, Robertson J, McInnes I. Cytokines as therapeutic targets in rheumatoid arthritis and other inflammatory diseases. Pharmacol Rev. 2015; 67: 280-309. doi: $10.1124 /$ pr.114.009639.

7. Aggarwal S, Gurney AL. IL-17: prototype member of an emerging cytokine family. J Leukoc Biol. 2002; 71: 1-8.

8. Moran EM, Mullan R, McCormick J, Connolly M, Sullivan O, Fitzgerald O, Bresnihan B, Veale DJ, Fearon U. Human rheumatoid arthritis tissue production of IL-17A drives matrix and cartilage degradation: synergy with tumour necrosis factor-alpha, Oncostatin $\mathrm{M}$ and response to biologic therapies. Arthritis Res Ther. 2009; 11: R113. doi: 10.1186/ar2772.

9. Katz Y, Nadiv O, Beer Y. Interleukin-17 enhances tumor necrosis factor alpha-induced synthesis of interleukins 1,6 , and 8 in skin and synovial fibroblasts: a possible role as a "fine-tuning cytokine" in inflammation processes. Arthritis Rheum. 2001; 44: 2176-84. doi: $\quad 10.1002 / 1529-0131(200109) 44: 9<2176:$ AIDART371>3.0.CO;2-4.

10. Nakae S, Nambu A, Sudo K, Iwakura Y. Suppression of Immune Induction of Collagen-Induced Arthritis in IL-17Deficient Mice. The Journal of Immunology. 2003; 171: 6173-7. doi: 10.4049/jimmunol.171.11.6173.

11. Wu C, Ying H, Bose S, Miller R, Medina L, Santora L, Ghayur T. Molecular construction and optimization of anti-human IL-1alpha/beta dual variable domain immunoglobulin (DVD-Ig) molecules. MAbs. 2009; 1: 339-
47. doi: 10.4161/mabs.1.4.8755.

12. Qi J, Kan F, Ye X, Guo M, Zhang Y, Ren G, Li D. A bispecific antibody against IL-1beta and IL-17A is beneficial for experimental rheumatoid arthritis. Int Immunopharmacol. 2012; 14: 770-8. doi: 10.1016/j. intimp.2012.10.005.

13. Silacci $\mathrm{M}$, Lembke $\mathrm{W}$, Woods $\mathrm{R}$, Attinger-Toller I, Baenziger-Tobler N, Batey S, Santimaria R, von der Bey U, Koenig-Friedrich S, Zha W, Schlereth B, Locher M, Bertschinger $\mathrm{J}$, et al. Discovery and characterization of COVA322, a clinical-stage bispecific TNF/IL-17A inhibitor for the treatment of inflammatory diseases. MAbs. 2016; 8: 141-9. doi: 10.1080/19420862.2015.1093266.

14. Fischer JA, Hueber AJ, Wilson S, Galm M, Baum W, Kitson C, Auer J, Lorenz SH, Moelleken J, Bader M, Tissot AC, Tan SL, Seeber S, et al. Combined inhibition of tumor necrosis factor alpha and interleukin-17 as a therapeutic opportunity in rheumatoid arthritis: development and characterization of a novel bispecific antibody. Arthritis Rheumatol. 2015; 67: 51-62. doi: 10.1002/art.38896.

15. Kim Y, Yi H, Jung H, Rim YA, Park N, Kim J, Jung SM, Park SH, Park YW, Ju JH. A Dual Target-directed Agent against Interleukin-6 Receptor and Tumor Necrosis Factor alpha ameliorates experimental arthritis. Sci Rep. 2016; 6: 20150. doi: 10.1038/srep20150.

16. Kanakaraj P, Puffer BA, Yao XT, Kankanala S, Boyd E, Shah RR, Wang G, Patel D, Krishnamurthy R, Kaithamana S, Smith RG, LaFleur DW, Barbas CF 3rd, et al. Simultaneous targeting of TNF and Ang2 with a novel bispecific antibody enhances efficacy in an in vivo model of arthritis. MAbs. 2012; 4: 600-13. doi: 10.4161/mabs.21227.

17. Chen Z, Wang L, Xu T, Wang Q, Kang L, Zhao Q. Generation of bispecific antibodies by $\mathrm{Fc}$ heterodimerization and their application. Curr Pharm Biotechnol. 2016; 17: 1324-1332. doi: 10.2174/1389201017666161018150553.

18. Feng Y, Zhao Q, Chen W, Wang Y, Crowder K, Dimitrov DS. A new bispecific antibody targeting non-overlapping epitopes on IGF2: design, in vitro characterization and pharmacokinetics in macaques. Exp Mol Pathol. 2014; 97: 359-67. doi: 10.1016/j.yexmp.2014.09.007.

19. Zhao Q, Feng Y, Zhu Z, Dimitrov DS. Human monoclonal antibody fragments binding to insulin-like growth factors I and II with picomolar affinity. Mol Cancer Ther. 2011; 10: 1677-85. doi: 10.1158/1535-7163.MCT-11-0281.

20. Chen W, Feng Y, Zhao Q, Zhu Z, Dimitrov DS. Human monoclonal antibodies targeting nonoverlapping epitopes on insulin-like growth factor II as a novel type of candidate cancer therapeutics. Mol Cancer Ther. 2012; 11: 1400-10. doi: 10.1158/1535-7163.MCT-12-0172.

21. Fischer N, Leger O. Bispecific antibodies: molecules that enable novel therapeutic strategies. Pathobiology. 2007; 74: 3-14. doi: 10.1159/000101046.

22. Chiu WC, Lai YP, Chou MY. Humanization and characterization of an anti-human TNF-alpha murine 
monoclonal antibody. PLoS One. 2011; 6: e16373. doi: 10.1371/journal.pone.0016373.

23. Griffin GK, Newton G, Tarrio ML, Bu DX, Maganto-Garcia E, Azcutia V, Alcaide P, Grabie N, Luscinskas FW, Croce KJ, Lichtman AH. IL-17 and TNF-alpha sustain neutrophil recruitment during inflammation through synergistic effects on endothelial activation. J Immunol. 2012; 188: 6287-99. doi: 10.4049/jimmunol.1200385.

24. Pelletier M, Maggi L, Micheletti A, Lazzeri E, Tamassia N, Costantini C, Cosmi L, Lunardi C, Annunziato F, Romagnani S, Cassatella MA. Evidence for a cross-talk between human neutrophils and Th17 cells. Blood. 2010; 115: 335-43. doi: 10.1182/blood-2009-04-216085.

25. Shahrara S, Pickens SR, Dorfleutner A, Pope RM. IL-17 induces monocyte migration in rheumatoid arthritis. J Immunol. 2009; 182: 3884-91. doi: 10.4049/ jimmunol.0802246.

26. Hwang SY, Kim JY, Kim KW, Park MK, Moon Y, Kim WU, Kim HY. IL-17 induces production of IL-6 and IL-8 in rheumatoid arthritis synovial fibroblasts via NF-kappaBand PI3-kinase/Akt-dependent pathways. Arthritis Res Ther. 2004; 6: R120-8. doi: 10.1186/ar1038.

27. Buckland J. Rheumatoid arthritis: Anti-TNF and anti-IL-17 antibodies--better together! Nat Rev Rheumatol. 2014; 10: 699. doi: 10.1038/nrrheum.2014.183.

28. Zhang M, Wang G, Tao Y, Zhang H. The proinflammatory effect and molecular mechanism of IL-17 in the intestinal epithelial cell line HT-29. J BUON. 2015; 20: 120-7. doi: 10.3748/wjg.v20.i47.17924
29. Taylor PC, Williams RO. Combination cytokine blockade: the way forward in therapy for rheumatoid arthritis? Arthritis Rheumatol. 2015; 67: 14-6. doi: 10.1002/ art.38893.

30. Bartok B, Firestein GS. Fibroblast-like synoviocytes: key effector cells in rheumatoid arthritis. Immunol Rev. 2010; 233: 233-55. doi: 10.1111/j.0105-2896.2009.00859.x.

31. Georganas C, Liu H, Perlman H, Hoffmann A, Thimmapaya B, Pope RM. Regulation of IL-6 and IL-8 expression in rheumatoid arthritis synovial fibroblasts: the dominant role for NF-kappa B but not C/EBP beta or c-Jun. J Immunol. 2000; 165: 7199-206. doi: 10.4049/jimmunol.165.12.7199.

32. Hot A, Zrioual S, Lenief V, Miossec P. IL-17 and tumour necrosis factor alpha combination induces a HIFlalpha-dependent invasive phenotype in synoviocytes. Ann Rheum Dis. 2012; 71: 1393-401. doi: 10.1136/ annrheumdis-2011-200867.

33. Garber K. Bispecific antibodies rise again. Nat Rev Drug Discov. 2014; 13: 799-801. doi: 10.1038/nrd4478.

34. Liu Z, Leng EC, Gunasekaran K, Pentony M, Shen M, Howard M, Stoops J, Manchulenko K, Razinkov V, Liu $\mathrm{H}$, Fanslow W, Hu Z, Sun N, et al. A novel antibody engineering strategy for making monovalent bispecific heterodimeric IgG antibodies by electrostatic steering mechanism. J Biol Chem. 2015; 290: 7535-62. doi: 10.1074/jbc.M114.620260. 